\title{
CIERRE, SELLADO Y REINSERCIÓN DE ANTIGUOS VERTEDEROS. EXPERIENCIAS EN IBEROAMÉRICA
}

\author{
Amaya LOBO GARCÍA DE CORTÁZAR ${ }^{1 *}$, Marcel SZANTÓ NAREA² y Susana LLAMAS ${ }^{3}$
}

${ }^{1}$ Universidad de Cantabria. Grupo de Ingeniería Ambiental, GIA. Avda. Los Castros s/n 39005. Cantabria. Santander. España

${ }^{2}$ Pontificia Universidad Católica de Valparaíso. Grupo de Investigación de Residuos Sólidos, GIRS. Escuela de Ingeniería en Construcción. Valparaíso. Chile

${ }^{3}$ Universidad Nacional de Cuyo. Facultad de Ingeniería. Centro de Estudios de Ingeniería de Residuos Sólidos, CEIRS. Mendoza. Argentina

*Autor para correspondencia: amaya.lobo@unican.es

(Recibido noviembre 2014; aceptado agosto 2015)

Palabras clave: relleno, posclausura, recuperación, vigilancia ambiental, lixiviados, biogás

\section{RESUMEN}

Al final de cualquier estrategia de gestión, independientemente de las directrices políticas y los recursos asignados, los residuos sólidos deben quedar almacenados en un sitio de disposición final. En Iberoamérica hoy en día una gran fracción de los residuos urbanos generados acaba en estos sitios, de los cuales poco más del $30 \%$ son rellenos sanitarios. El resto son vertederos controlados o vertederos a cielo abierto en los que las condiciones de protección de la población y el medio ambiente frente a la contaminación de los residuos son insuficientes. Independientemente de las condiciones de disposición, terminada su capacidad de recepción de residuos el lugar constituye un pasivo ambiental que debe ser controlado durante muchos años para evitar daños que pueden ser graves. De hecho las normas establecen la obligatoriedad de cerrar y reinsertar estos lugares, con períodos de vigilancia ambiental de más de 20 años tras la clausura. En Iberoamérica hay ejemplos de buenas prácticas en esta fase de la vida del vertedero. Como ayuda para otros casos, este trabajo, basado en la experiencia y recopilación de informaciones técnicas, propone la metodología básica a seguir en un proyecto de este tipo y presenta varios ejemplos de clausura y reinserción de vertederos en esta parte del mundo.

Key words: Landfill post-closure, recovery, environmental monitoring, leachate, biogas

\begin{abstract}
Regardless of the policy guidelines and allocated resources, at the end of any management strategy, solid waste must be stored in a disposal site. Nowadays in Iberoamerica a large fraction of generated urban waste ends at these sites, of which just over $30 \%$ are sanitary landfills. The rest are controlled or uncontrolled dumping sites in which the conditions of protection for the population and the environment against waste pollution are inadequate. Independently of the disposal conditions, after reaching landfill capacity, the site constitutes an environmental liability that must be controlled for many years to prevent damage which may be severe. In fact, the rules stipulate the obligation to close and reintegrate these sites, with periods of environmental surveillance of more than 20 years after closure. In Iberoamerica there are examples of good practice at this stage of landfill life. As a help for different cases, based on experience and a compilation of technical information, this paper proposes a basic methodology to be followed in a project of this type, and presents several examples of landfill closure and rehabilitation in this region of the world.
\end{abstract}




\section{INTRODUCCIÓN}

El depósito en el terreno debe ser el punto final en todo esquema de gestión de residuos. Previamente se habrá intentado reutilizar, reciclar o aprovechar energéticamente los residuos; sólo el rechazo de estos procesos debería acabar en los rellenos. Con esta estrategia, algunos países europeos, como Alemania, Holanda y Suecia, están muy cerca de lograr el "vertido cero", con menos del $5 \%$ de los residuos municipales llevados a disposición final (Eurostat 2013). Sin embargo, frente a distintas alternativas de reuso o valorización de la basura como recurso, la disposición en el terreno o depósito es una opción barata, si se considera sólo el costo económico y no el ambiental. Además no requiere especial diseño en fases anteriores de la gestión (no necesita, por ejemplo, una recolección selectiva previa), instalaciones complejas ni preparación técnica muy especializada.

Por eso la disposición final en el terreno es el destino mayoritario de los residuos municipales generados en muchos países, como en toda América Latina y el Caribe (ALyC). En este entorno una gran parte de los residuos recolectados acaba en sitios de disposición final en el terreno: poco más del $50 \%$ son gestionados en rellenos sanitarios (Tello et al. 2010). Aproximadamente el $18 \%$ son dispuestos en vertederos controlados, y hasta un $23 \%$ en botaderos a cielo abierto. Independientemente de las condiciones del lugar donde se depositen, teniendo en cuenta las tasas de generación de residuos municipales en América Latina (550 000 t/año en 2010), los residuos generados durante 20 años depositados en un relleno sanitario medio de altura $30 \mathrm{~m}$ ocuparían, a una densidad media de $800 \mathrm{~kg} / \mathrm{m}^{3}, 46$ ha.

Sin un diseño y operación adecuados, estos lugares pueden causar impactos muy graves. La migración libre de los lixiviados, por ejemplo, puede llegar a contaminar cursos de agua superficiales o subterráneos. Las emisiones gaseosas pueden ser tóxicas, explosivas y causar molestias por olores en el propio relleno y en áreas circundantes. Además la mayor parte de los gases generados en vertederos de residuos municipales son metano y dióxido de carbono, gases de efecto invernadero (Tchobanoglous et al. 1994). Por otro lado, cuando no ha habido una planificación previa, la acumulación de basuras se realiza en grandes alturas, sin control de las pendientes y las condiciones de compactación. Aun en sitios controlados debe realizarse un seguimiento geotécnico continuo para evitar el movimiento de grandes masas de residuos, que pueden causar desastres ambientales y humanos, como en los casos tristemente conocidos de Bens en España, Doña Juana en Colombia o Loma Los Colorados en Chile (Colomer y Gallardo 2007).

Estos riesgos pueden prolongarse largamente después de haber cesado las actividades de disposición de residuos. La extensión de la vida activa de los rellenos como riesgo potencial en el entorno es decir, como pasivo ambiental, es motivo de numerosas investigaciones desde hace algunos años, como las recopiladas en (Laner et al. 2012). Hoy en día se ha comprobado que, en todo caso, la emisión de contaminantes puede extenderse más allá de 20 años después de haber abandonado los residuos. Por eso las normativas en distintos países van incorporando la obligatoriedad para las entidades explotadoras de vertederos de hacerse cargo (técnica y económicamente) de un período de vigilancia postclausura de al menos 20 (como en el caso de la legislación chilena, [MINSAL 2007]) o 30 años (como en caso de la legislación española [MAM 2001]).

A pesar de estos riesgos y las posibles molestias directas a la población (olores, objetos volantes, etc.), los rellenos suelen localizarse en lugares cercanos a las áreas habitadas, para minimizar los costes de transporte de residuos. A veces incluso el crecimiento del tejido urbano acaba absorbiendo el entorno del vertedero, quedando éste inmerso en la ciudad, ocupando un espacio muy amplio de gran valor para la ciudadanía. Esto potencia el interés de recuperar el relleno para, más allá de eliminar el pasivo ambiental que representa, reintegrar el espacio para otros usos comunitarios.

Existen distintas estrategias para afrontar la recuperación y la reinserción de un sitio de disposición final, con experiencias muy variadas en todo el mundo. Con objeto de servir de referencia

\section{CUADRO I. OPCIONES DE RECUPERACIÓN Y} REINSERCIÓN

\begin{tabular}{l}
\hline Recuperación \\
Aislamiento o sellado \\
Retirada y traslado del residuo \\
Recuperación in situ \\
\hline Reinserción \\
Integración paisajística \\
Uso recreativo (campo deportivo, parque) \\
Cultivo agrícola \\
Uso comercial (aparcamiento, vía de comunicación, \\
polígono industrial) \\
Parque energético (solar, eólico) \\
\hline
\end{tabular}


cuando se afrontan estas actuaciones, este artículo comienza con una breve descripción de las distintas opciones de recuperación y reinserción que se han practicado en el mundo (cuadro I). A continuación se describen algunos casos de buenas prácticas en este campo desarrollados en el ámbito iberoamericano y, finalmente, se reúnen los elementos fundamentales a considerar en un proyecto de este tipo cuando se opta por la solución "tradicional" de cierre, clausura y reinserción, que es lo más habitual y aconsejable hoy en día en Iberoamérica.

\section{OPCIONES DE RECUPERACIÓN Y REINSERCIÓN}

\section{Recuperación}

La puesta a punto de un depósito de basuras que se cierra pasa por su recuperación, reduciendo los riesgos ambientales hasta hacerlos compatibles con el nuevo uso, y su reinserción, preparando el terreno e incorporando los elementos que albergará.

Existen distintas estrategias para recuperar estos depósitos. Las necesidades son diferentes dependiendo del tamaño del mismo, su historia, la sensibilidad del entorno y el valor del terreno en que se asienta. Las opciones a considerar varían, por ejemplo, ante un antiguo microvertedero no controlado situado en un área rural o un gran vertedero urbano rodeado por asentamientos de población.

Existen tres enfoques básicos para recuperar el terreno: aislar los residuos para evitar emisiones incontroladas de contaminantes, retirar los residuos para su tratamiento o depósito en otro lugar, o tratarlos in situ hasta reducir sus potenciales impactos a niveles admisibles.

\section{Aislamiento o Sellado}

El sellado es la solución tradicional. Se trata de aislar el depósito instalando sobre su superficie capas poco permeables de distintos materiales. Estas capas limitan el paso del agua de lluvia a través del residuo y por tanto la formación de más lixiviados, y retienen también el gas generado, evitando su escape libre hacia la atmósfera.

Si el depósito se asienta sobre una zona permeable no acondicionada previamente, el sellado superficial no asegura el fin de las emisiones, pues éstas pueden continuar a través del contacto con el terreno. Por eso, según el estado del vertedero y la vulnerabilidad del medio, el sellado debe ir acompañado de otras obras para recolección/intercepción de lixiviados y gases (ITCR 2006). En los apartados siguientes se muestran las acciones más importantes a considerar en este tipo de solución.

\section{Retirada}

Cuando el volumen de residuos es pequeño, el medio especialmente sensible o el nuevo uso incompatible con los riesgos del vertedero, se plantea trasladar los residuos a otro lugar con condiciones adecuadas para depositarlos. Esta solución puede combinarse con labores de separación o tratamiento para recuperar alguno de los materiales vertidos, como el material de cobertura (Hogland et al. 2004), o la fracción combustible de los residuos (Canaleta y Ripoll 2012), lo que se conoce como "minería de vertederos". A veces incluso se ha planteado la minería como alternativa en sí misma, aunque no hubiese necesidad de traslado. Sin embargo, aunque desde el punto de vista ambiental parece ventajosa, pues elimina riesgos, a la vez que permite recuperar recursos, para vertederos de residuos municipales (RM) hoy en día esta solución no es rentable desde el punto de vista económico, aunque es motivo de nuevos desarrollos para que lo sea (Krook et al. 2012).

\section{Recuperación in situ}

La solución tradicional de sellado tiene un efecto de enclaustramiento de la contaminación. Se evitan las emisiones (al menos temporalmente, mientras los elementos de sellado estén operativos) pero, al evitar el paso de líquido quedando el residuo seco, se detienen los procesos de descomposición, y por tanto se deja latente materia que en el futuro se podrá degradar.

Una opción para reducir los riesgos en el tiempo es acelerar los procesos "conflictivos" para que el relleno sea ambientalmente estable lo antes posible. Puesto que la fuente principal de contaminación en los RM es orgánica, los rellenos de basuras municipales pueden "biorrecuperarse" induciendo las condiciones adecuadas para que los microorganismos degraden rápidamente este tipo de residuos. Este es el objetivo de las prácticas de "vertedero sostenible" (Scharff 2007), con las que se trata de eliminar su potencial impacto tan pronto como sea posible. Para ello se convierte el relleno en un reactor o biorreactor (Reinhart y Townsend 1998) donde, mediante introducción de líquidos (lixiviados o líquidos externos) y control de otras variables, se van potenciando las reacciones de degradación de los contaminantes, hasta que lo remanente deja de ser una amenaza para el entorno.

Esta estrategia puede aplicarse sobre rellenos ya abandonados o en vertederos en operación (ITCR 2006). Es más costosa y requiere un mayor control 
que la tradicional, pero a cambio reduce los riesgos ambientales a largo plazo y por tanto el tiempo de vigilancia postclausura. Por otro lado, al permitir el control de los procesos biológicos, puede ayudar a obtener un mejor aprovechamiento del gas de vertedero. Sin embargo, implica la inyección de líquidos que acaban contaminados, así como mayores flujos de contaminantes, de manera que sólo es aplicable en depósitos convenientemente aislados del entorno, con una impermeabilización adecuada.

\section{Reinserción}

El uso del terreno donde se asienta el vertedero una vez clausurado debe ser compatible con los procesos que este sufrirá en el tiempo y las medidas de protección instaladas, así como con las labores de seguimiento y mantenimiento postclausura.

Más allá de la integración paisajística del lugar, introduciendo una cobertura de suelo y siembra de especies herbáceas, desde hace más de medio siglo se han desarrollado prácticas exitosas de reinserción de vertederos para usos muy variados. Entre los procesos que más condicionan el uso final del terreno se encuentran los de asentamiento de los residuos. La instalación de elementos pesados, con reparto puntual de cargas sobre la superficie, puede dar lugar a asientos diferenciales que provoquen el fallo de la estructura. Por eso el uso más común de rellenos reinsertados es recreativo, como parque o campo deportivo (futbol, béisbol, golf). Existen numerosos ejemplos en Iberoamérica, como el parque La Cañamera, en Santiago de Chile, el polideportivo Perez Perazo en Quito (Ecuador) o el parque Los Ensueños, en Barranquilla (Colombia).

Con una cobertura apropiada y un sistema suficiente de control de emisiones, también es posible destinar el "nuevo" lugar para cultivo agrícola, como uno de los ejemplos que se presentan a continuación, o el Fundo La Gloria, creado en Limache (Chile).

Otra opción, especialmente buscada en áreas que han quedado inmersas en el tejido urbano, es el uso como aparcamiento (caso del vertedero Macul, en Santiago de Chile), zona comercial (como el centro de la Ciudad Jardín Bicentenario en Ciudad Nezahualcóyoti, Mexico, situada sobre el antiguo tiradero de Neza), vía de comunicación, o como polígono industrial con asentamiento de naves.

Un planteamiento creciente en los últimos años es el del uso de antiguos vertederos como parques de generación de energía renovable. Se trata de aprovechar la localización de estos lugares, cercanos a vías de comunicación y otras infraestructuras, y el escaso valor del suelo que ocupan, para transformar el pasivo ambiental en un activo valioso, teniendo en cuenta sobre todo la demanda energética actual (Toth et al. 2013).

Existen ya varias experiencias en el mundo de colocación de paneles fotovoltaicos sobre la cobertura (Tansel et al. 2010, Craig 2011). Se han desarrollado incluso láminas flexibles que simplemente quedan apoyadas sobre la superficie, adaptándose a deformaciones en el tiempo, para evitar la necesidad de cimentar las placas. En el ámbito iberoamericano esta solución todavía no está extendida. En España se están aprobando últimamente algunos proyectos de sellado con esta solución, como el de parte del vertedero de Salto del Negro, en Canarias, al tiempo que se desarrollan proyectos para optimización de esta tecnología, como el Proyecto Itzulbide (ACLIMA 2014). Estas soluciones son particularmente ventajosas al aplicarlas en vertederos con sistemas de aprovechamiento del gas que se genera, porque se puede adaptar gran parte de la infraestructura eléctrica instalada para este último, e ir implantando el sistema de energía solar a medida que se va reduciendo la generación del gas (USEPA 2012).

Otra opción en la misma línea es instalar generadores eólicos sobre el vertedero. Este caso es más complejo, pues se debe preparar el vertedero para que la cimentación de los generadores sea segura, pero ya existen experiencias exitosas, como la del vertedero de Frey Hill en Pensilvania, donde se instalaron dos turbinas de 1.6 MW (Trotti 2011)

\section{METODOLOGÍA BÁSICA PARA EL CIERRE Y REINSERCIÓN}

Desde comienzos de este siglo se han editado en Iberoamérica distintos documentos con orientaciones generales sobre el cierre de sitios de disposición final (GTZ 2002, CONAM/CEPIS/OPS 2004). Sintetizando las propuestas de estas guías y otra literatura consultada junto con la experiencia de los autores, se ha reunido, en los párrafos siguientes, una síntesis de los aspectos fundamentales a considerar para abordar un plan de rehabilitación convencional, basado en el sellado de los residuos.

Gran parte de los sitios de disposición final a cerrar en ALyC, el 78 \% en 1997 (Acurio et al. 1997), son vertederos incontrolados o a cielo abierto, que no cumplen con las condiciones mínimas de protección del entorno. La figura 1 recoge el proceso de clausura, sellado y reinserción adecuado para estos lugares. El cierre pasa primero por definir una solución de saneamiento, que resuelva adecuadamente el pasivo 


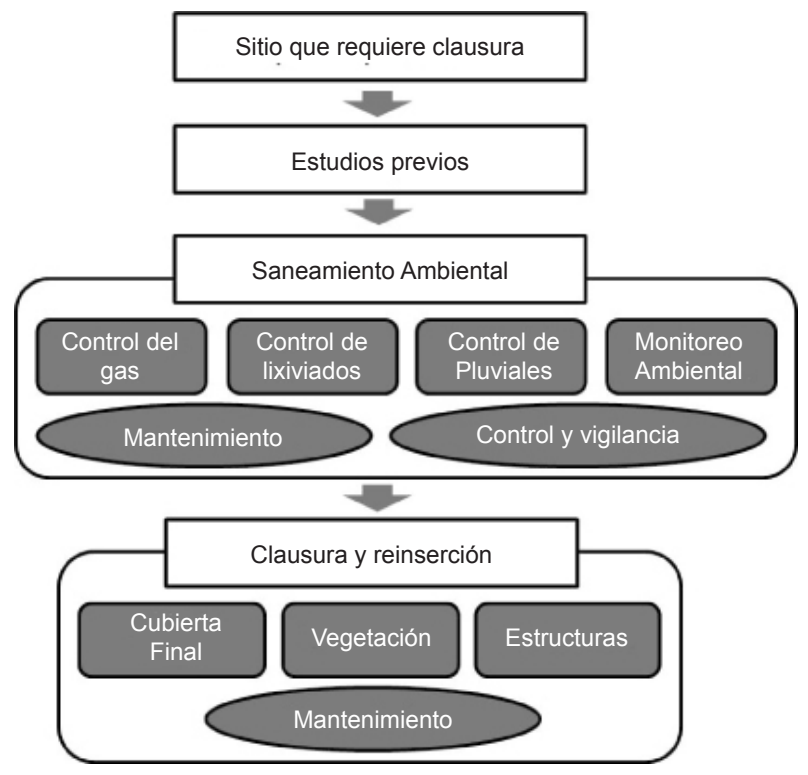

Fig. 1. Diagrama esquemático del proceso de cierre, clausura y reinserción de antiguos vertederos.

ambiental. Esta fase incluye las actuaciones para controlar el biogás, los lixiviados y la escorrentía superficial, así como para realizar un seguimiento ambiental del lugar. Además preverá el mantenimiento posterior de estas instalaciones, junto con las operaciones de control y vigilancia ambiental. Una vez previsto el saneamiento, puede entonces definirse la solución de clausura adecuada al uso elegido, con la cubierta final, casi siempre vegetación de la superficie, e instalación de estructuras de distintos tipos. Para estos elementos se definirá asimismo el plan de mantenimiento a largo plazo.

En conjunto, al final se trata de dotar al vertedero de unos elementos de cierre o protección ambiental (cubierta, control de biogás, lixiviados y escorrentía) y otros de rehabilitación (vegetación, estructuras).

\section{Estudios previos}

Las medidas necesarias para rehabilitar un antiguo vertedero dependen del riesgo que este supone para el entorno. El punto de partida es, por tanto, la evaluación de riesgos del lugar, que deberá tener mayor o menor detalle según el tipo de instalación, su tamaño, el tiempo que lleva cerrado y la naturaleza de los residuos vertidos.

La evaluación comienza con un análisis preliminar para determinar la importancia de los riesgos potenciales. Este primer estudio puede basarse en la información disponible e inspecciones del lugar. Se trata de identificar los impactos más probables a partir de información sobre la fuente de riesgo (el vertede- ro), las rutas de exposición (canalizaciones, cunetas, cobertura, terreno circundante) y los posibles receptores (ecosistemas acuáticos superficiales o subterráneos, animales o personas). Existen distintas guías de referencia en este proceso (por ejemplo Calvo et al. 2005, ME 2001). El riesgo es elevado si coinciden una fuente relevante, una ruta efectiva y receptores sensibles. Cuando falta alguno de estos elementos la probabilidad del impacto es mucho menor. Un vertedero en estado de degradación activa y por tanto generando biogás, constituye un riesgo muy reducido si se encuentra en una zona rural, sin edificios cercanos y, sin embargo, representa un riesgo muy elevado si existen edificios o viviendas donde el gas puede quedar atrapado. $\mathrm{Si}$, como resultado de este primer estudio de aproximación, se concluye que los riesgos de la instalación son relevantes, entonces se deben desarrollar estudios de detalle. Estos estudios permiten inicialmente acotar el riesgo implicado, y después definir adecuadamente las soluciones de saneamiento y cierre. Si, por el contrario, no existe riesgo significativo, no se justifica realizar mayores esfuerzos de recopilación de información.

En vertederos construidos y operados como rellenos sanitarios, cumpliendo con los requisitos de la normativa, no son necesarios estos estudios iniciales, pues ya se dispone de información suficiente para conocer el estado de partida. De hecho, siguiendo las directrices normativas generales, en el proyecto inicial de autorización de las instalaciones ya se habrá previsto una solución para el cierre, así como el uso postclausura.

Un caso opuesto es el de grandes vertederos, como Bordo Poniente, en la ciudad de México, recientemente clausurado, con una larga historia conocida de efectos y amenazas al medio y la salud humana. En estos casos tampoco es necesario el filtrado inicial para establecer la necesidad de actuación, aunque sí estudios previos para definir el proyecto de saneamiento y cierre. A nivel de planificación, sin embargo, cuando existen varios rellenos sobre los que se debe actuar, sí es importante la fase de evaluación de riesgos, al menos para priorizar las inversiones.

Establecida la necesidad de cierre y reinserción, el trabajo en vertederos abandonados debe comenzar con estudios preliminares que determinen las opciones de recuperación, en función del estado actual del lugar y sus efectos potenciales. Estos trabajos comienzan con recopilación de antecedentes y sectorización del área en caso necesario, y deben incluir los aspectos reflejados en el cuadro II (Rondón y Szantó 2012). 
CUADRO II. ASPECTOS A CONSIDERAR EN LOS ESTUDIOS PREVIOS AL CIERRE Y REINSERCIÓN DE RELLENOS*

Estratigrafías del subsuelo, con calicatas de reconocimiento

Evaluación hidrogeológica para detectar el nivel freático natural

Determinación de presencia y migración del biogás

Caracterización de los materiales depositados (composición, estado de degradación, tipo de cobertura)

Determinación de presencia y migración de lixiviados y su caracterización

Evaluación geotécnica (ensayos de penetración, prospección geofísica, ensayos de carga)

*En rellenos sanitarios gran parte de esta información está disponible al definir el sellado.

Esta fase inicial del proyecto es fundamental. El objetivo es definir lo mejor posible el estado del vertedero, a un coste razonable, para buscar luego la mejor solución desde un punto de vista técnico, social y económico. El costo variará en función de la magnitud del sitio, así como del entorno. Los costes de perforación, por ejemplo, dependen de la profundidad, y si los lixiviados están confinados habrá que perforar para sacar muestras; lo mismo ocurre con el biogás y el agua subterránea.

\section{ELEMENTOS DEL CIERRE}

La solución de saneamiento y cierre debe ser diseñada específicamente para cada lugar, e irá siempre asociada al uso final objetivo. En muchos vertederos incontrolados de ALyC, como Cali (Colombia), El Pozo (Argentina), Puerto Montt y Antofagasta (Chile), se encuentran asentamientos de villas miseria, chabolas o mediaguas alrededor o sobre los residuos. Las primeras medidas deben considerar la reubicación de la población en riesgo y clausurar las instalaciones frente al acceso incontrolado de personas. Se trata de una fase delicada y compleja desde el punto de vista social (Esteban García et al. 2001). La solución desde esta perspectiva pasa por la reinserción social de las poblaciones asentadas en los residuos, los denominados recicladores de base. Existen en Iberoamérica diversas experiencias, como la desarrollada en el vertedero El Molle de Valparaíso, Chile, que inició el proceso de cierre con un programa de reinserción de los recicladores de base.

Desde el punto de vista técnico, en todo caso se debe considerar la capa de cobertura final, la evacuación de las aguas superficiales externas e internas, la intercepción y gestión de los lixiviados y el control de los gases generados. Para estos elementos se tendrá en cuenta no sólo el efecto de cada uno sobre los riesgos identificados, sino también su interacción. La cobertura del vertedero con una capa impermeable de arcilla, por ejemplo, reduce la generación de lixiviados y el acceso de vectores al residuo, pero también retiene el gas que se genera, y provoca cambios en su migración que pueden incrementar su potencial acumulación en instalaciones del vecindario.

Por otro lado, un factor primordial al definir la solución es el presupuesto disponible, pues la clausura implica costes importantes, que habitualmente sobrepasan los $190000 € /$ ha (ME, 2001; Duffy 2005, MDE, 2010).

\section{Capa de cobertura final}

Los trabajos de clausura deberían comenzar al cesar las actividades de vertido, pero pueden plantearse progresivos, mientras se deja entrar residuo incluso como "relleno" para ir alcanzando la cota final. En grandes instalaciones, incluso, las distintas zonas del vertedero se deben ir cerrando a medida que van agotando su capacidad, e instalando progresivamente la cobertura final.

La primera acción es asegurar el control de accesos a las zonas abandonadas y de vectores (ratas, moscas, pájaros). Habitualmente las obras comienzan con un reperfilado de la superficie para atenuar pendientes fuertes que puedan comprometer las capas de cobertura y adecuar la topografía al uso posterior. Muchas veces es necesario mover y recompactar el residuo, lo que conlleva casi siempre emisiones de polvo y gases que generan molestias por olores en residencias cercanas. Para minimizarlas se puede trabajar en situaciones atmosféricas favorables, por ejemplo cuando la dirección del viento contribuya a diluir las emisiones antes de su llegada al receptor. A veces se han llegado a emplear pantallas antiolor (Bolton 2012).

Para evitar la erosión por viento y/o la escorrentía y asegurar la estabilidad, es conveniente limitar la pendiente de los taludes por debajo de $1 \mathrm{~V}: 3 \mathrm{H}$ (ISWA 2010). El límite puede venir dado por la resistencia al rozamiento de los materiales de cobertura (cuando se utiliza arcilla o geomembrana los planos de contacto entre capas suelen ser el plano crítico de deslizamiento), o también por el uso final buscado. 
Si se piensa, por ejemplo, en que la superficie sirva de pasto para ganado, además de contar con las capas de cobertura adecuadas, la pendiente debe ser menor (ME 2001).

Durante los primeros años tras el cese de las operaciones los vertederos pueden sufrir asentamientos importantes (de más de un $20 \%$ [Edil et al. 1990]), que si no son homogéneos en su superficie (y no lo suelen ser, por la heterogeneidad del residuo y en general de los materiales empleados en la construcción), estropean la capa de sellado y las instalaciones de clausura. Por eso a veces se instala una cobertura provisional, de al menos $30 \mathrm{~cm}$ de suelo compactado, antes de construir la capa de sellado definitiva, al cabo de 2 a 4 años. Para vertederos abandonados hace más de 10 años esta cobertura provisional no es necesaria.

La capa de cobertura final a instalar depende fundamentalmente de la existencia de un sistema de aislamiento de fondo y de evacuación de los lixiviados adecuado. Cuando estos no existen y la precipitación neta del lugar (lluvia menos evapotranspiración) es significativa, la capa de sellado debe ser lo más impermeable posible, para reducir la cantidad de lixiviado en el futuro y por tanto sus impactos potenciales (ME 2001).

El objetivo de la capa de cierre es doble. Por un lado, evitar los riesgos de contacto con el residuo y de la emisión incontrolada de contaminantes (en forma de gas o de líquido) y por otro constituir un sustrato adecuado para los usos posteriores. Ambos objetivos deben cumplirse durante muchos años.

La solución ideal cuando se busca el aislamiento incluye una capa de regularización de al menos $50 \mathrm{~cm}$ de material compactado directamente sobre los residuos, para adaptar la superficie al perfil deseado y estabilizar zonas blandas (MAM 2006). Cuando el vertedero se encuentra todavía en fase activa de generación de gases, sobre la regularización se coloca una capa de ventilación, de material granular de alta permeabilidad de al menos $30 \mathrm{~cm}$ de espesor, que permita su movimiento y recogida en los puntos deseados, para evitar su acumulación dentro del vertedero, que puede llevar a sobrepresiones peligrosas, e incluso a romper las capas superiores de cierre. Sobre ésta, normalmente protegida con un geotextil, se coloca la capa de sellado. Para ello se utilizan capas de arcilla compactada, geomembranas ó geocompuestos arcillosos. La elección de un material u otro depende de la disponibilidad local de los mismos, el costo y también de condicionantes técnicos. Las capas de arcilla, por ejemplo, deben quedar bien protegidas en climas extremos frente a la desecación o los ciclos de hielo / deshielo que las agrietan, colocando espesores suficientes de suelo o geomembranas complementarias. A veces esta sucesión de capas se completa con una geomalla estructural, para aumentar la capacidad portante y la estabilidad del conjunto, evitando asientos diferenciales pronunciados (ME 2001).

La figura 2 presenta esquemas de distintas opciones de cobertura final, ordenadas de mayor a menor costo. La solución descrita anteriormente (opción A en la figura) es costosa y no siempre asumible. Puede suponer desde $135000 € /$ ha hasta más de $400000 € /$ ha sin considerar la capa de ventilación (ME 2001; Duffy 2005), dependiendo de los materiales elegidos y los espesores de las capas. Una opción intermedia que ha demostrado ser eficaz en distintos proyectos en $\mathrm{ALyC}$, es la colocación de al
OPCIÓN A

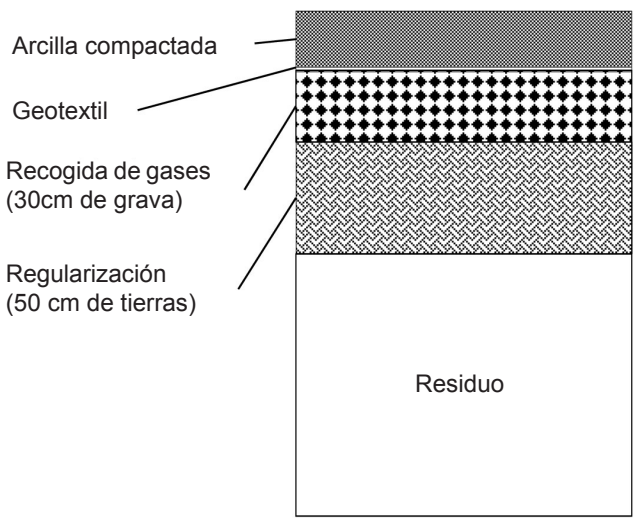

OPCIÓN B

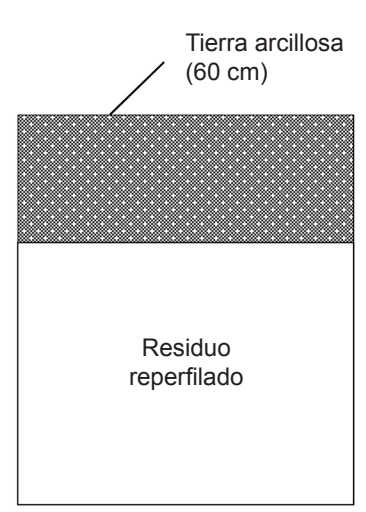

OPCIÓNC

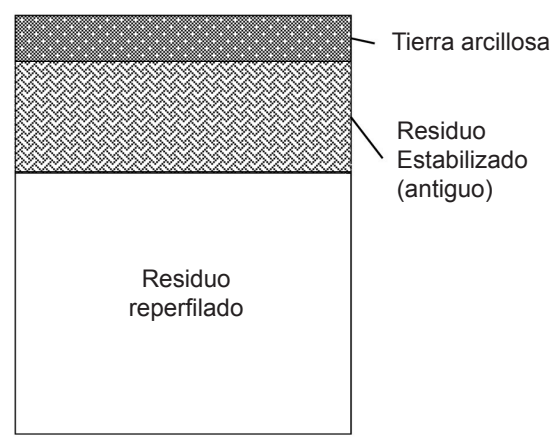

Fig. 2. Alternativas de sellado. Opciones con distinta complejidad y costo 
menos $60 \mathrm{~cm}$ de material arcilloso sobre el residuo previamente reperfilado donde sea necesario.

Según la disposición de materiales en el área, aun esta solución intermedia puede ser económicamente inabordable, cuando la magnitud del proyecto no justifica la inversión o el presupuesto está limitado. Muchas veces los vertederos asociados a pequeños municipios con recursos escasos son antiguos lugares donde el residuo ha ido degradándose en contacto directo con el aire, sin cobertura. Como resultado de los procesos aeróbicos los residuos han quedado bastante estabilizados: solo queda la fracción degradable lentamente, cuyas emisiones, al ser graduales, son más fáciles de controlar. Una solución de cierre para estos casos (como en varios de los vertederos descritos en los párrafos siguientes), es reducir el espesor de tierras externas necesarias, agregando material estabilizado del propio vertedero en la cobertura (opción $\mathrm{C}$ en la figura 2). Sobre este material se desarrollan bacterias metanotróficas que reducen las emisiones difusas superficiales y, con el paso del tiempo, crece vegetación que reintegra el área en el paisaje.

La necesidad de tierras de préstamo en mayor o menor espesor depende del estado de degradación del vertedero: estabilidad del residuo y potencial metanogénico. Por otro lado, si la migración superficial de biogás es importante, es recomendable colocar sobre la cobertura una capa de materia orgánica estabilizada o compost, que permitirá un abatimiento de metano por acción de baterias metanotróficas (GRS-PUCV 2004).

\section{Evacuación de las aguas superficiales}

Para evitar la entrada de agua al vertedero y la erosión se debe minimizar la escorrentía sobre la cobertura. Con este objetivo se deben instalar cunetas perimetrales que intercepten las aguas de lluvia externas para que no lleguen a la zona clausurada. Por otro lado, las pendientes superficiales deben ser suficientes para evitar encharcamientos, previendo incluso los efectos de asentamiento a lo largo del tiempo. Se instalarán drenes de intercepción de la escorrentía al menos cada $6 \mathrm{~m}$ de altura, y un sistema de conducciones de evacuación (combinación de cunetas y tubos), que reduzca en lo posible las distancias recorridas por el agua sobre la superficie (ME 2001).

Una opción para la evacuación de las aguas superficiales es su aprovechamiento para riego de la propia superficie sellada, tras su almacenamiento y retención de los sólidos arrastrados en lagunas de regulación.

\section{Control de los gases}

Las emisiones de gas de vertedero deben controlarse para evitar la exposición a su toxicidad, generación de molestias por malos olores, explosividad en las cercanías, y para reducir su contribución al efecto invernadero. Por otro lado, por su elevado contenido en metano, cuando los volúmenes generados son importantes, puede ser ventajoso su aprovechamiento para obtención de energía eléctrica y/o calor. Esta opción suele ser viable cuando pueden extraerse al menos $300 \mathrm{~m}^{3} / \mathrm{h}$ de biogás con más del 50 $\%$ metano, valor habitual en vertederos con más de 150000 t de residuo con contenido orgánico superior al $50 \%$ (EA 2004, FEMP 2011)

Cuando se detecta un problema de migración del gas en el exterior, la solución pasa por construir sistemas de intercepción en el perímetro del relleno. Estos sistemas consisten en pantallas o zanjas excavadas en el terreno y rellenadas de material de alta permeabilidad para desviar la trayectoria de los gases, o de material de baja permeabilidad (arcillas) para detener el flujo hacia las zonas a proteger (Tchobanoglous et al. 1994).

Para vertederos medianos y mayores y de cierta profundidad (más de $5 \mathrm{~m}$ ), el control del gas requiere la instalación de pozos de extracción entre los residuos. El sistema de extracción puede ser pasivo, en los vertederos con menos generación de gas, o activo. En éste último los pozos se conectan entre sí mediante colectores en los que se establece un vacío mediante soplantes, para conducir el gas hasta una antorcha central donde es quemado para destrucción de los componentes más peligrosos (Carreras 1998).

Si los volúmenes generados son bajos se opta por la extracción pasiva o ventilación, mediante pozos distanciados aproximadamente $25 \mathrm{~m}$ (se considera un radio de influencia medio de cada pozo de venteo entre 20 y $30 \mathrm{~m}$ ). Las chimeneas deben sobresalir al menos $2.5 \mathrm{~m}$ sobre la superficie, para evitar problemas de acceso a su interior, o el contacto directo con el biogás de los nuevos usuarios del terreno (Szantó et al. 1996).

Si la cantidad de gas generado requiere extracción activa puede utilizarse chimeneas o pozos verticales $\mathrm{o} / \mathrm{y}$ horizontales. En el caso de las chimeneas la separación puede ser de 50 a $80 \mathrm{~m}$, lo que conduce a 1 a 5 pozos por ha (Carreras 1998).

\section{Gestión de los lixiviados}

Al impedir la infiltración, la capa de sellado superficial provoca una reducción del volumen de 
lixiviados a lo largo del tiempo. En todo caso la contaminación no se detiene, de manera que si se han encontrado rutas de migración de los lixiviados a través del contorno que supongan riesgo, se debe hacer lo posible por detenerlas, mediante drenes de intercepción o zanjas de material drenante.

Los lixiviados del vertedero son líquidos muy contaminados. En vertederos de RM la contaminación es fundamentalmente orgánica, pudiendo aparecer también componentes minoritarios peligrosos, como metales pesados, según los residuos vertidos. La composición del lixiviado varía a lo largo de la vida del vertedero. A medida que envejece quedan los compuestos menos biodegradables y otros componentes, como el nitrógeno amoniacal, que pueden complicar su depuración.

El sellado del vertedero facilita la gestión del lixiviado, pues reduce su volumen, pero en consecuencia favorece su concentración, haciéndolos más contaminantes. El proyecto de cerrado debe contemplar, bien su tratamiento in situ con una depuradora adecuada y adaptable en el tiempo, bien su transporte para tratamiento en otras instalaciones (Tchobanoglous et al. 1994).

\section{Reinserción}

Controlado el problema ambiental mediante la solución de clausura, se pueden acometer las obras de reinserción. En todo caso, como se viene comentando, ambas soluciones deben proyectarse simultáneamente, pues son totalmente interdependientes.

\section{Vegetación}

En los casos más habituales, de rehabilitación paisajística o recuperación como parque, por ejemplo, el nuevo uso requiere la plantación de especies vegetales. El objetivo de revegetar el vertedero es múltiple, porque además de cumplir un objetivo estético, las plantas ayudarán a estabilizar la superficie y reducir la erosión.

La solución más simple es la plantación de especies herbáceas, de rápido desarrollo y raíces someras, pero también se pueden plantar arbustos y árboles. Las opciones de revegetación dependen de la solución de cobertura. Cuando la capa no retiene la emisión de gases éstos pueden resultar tóxicos para las plantas. Por otro lado, el espesor de suelo y tierra debe ser suficiente para el crecimiento de las raíces. Para árboles y arbustos pueden reservarse zonas donde los vertidos biodegradables hayan sido menores, y por tanto se prevea menor emisión de gas, o prever mayores espesores de cobertura en algunas áreas. Asimismo se pueden establecer diferencias entre taludes del vertedero, según su orientación (más o menos soleada, húmeda, sometida a vientos, etc.).

El contenido de nutrientes, la capacidad de intercambio iónico o la estructura de la capa superficial son también fundamentales para el desarrollo de la vegetación. A veces se añade acolchado para mejorar estas condiciones (ME 2001). Como las obras de construcción o ampliación del relleno obligan a retirar el suelo original, puede crearse un almacenamiento de mantillo local, que en la clausura favorecerá el desarrollo de especies autóctonas.

Puesto que el desarrollo de la vegetación depende de las condiciones locales (climatología, tipos de suelo), es difícil establecer unas indicaciones generales sobre la plantación. Al tratarse de un ambiente adverso, se deben seleccionar especies cuya capacidad de desarrollo en estas condiciones esté contrastada. Existe experiencia de plantación de especies de todo tipo, desde herbáceas hasta arbustos y árboles sobre residuo, y en distintas climatologías (Tchobanoglous et al. 1994, Olaeta et al. 1997).

Cuando el objetivo es restaurar paisajísticamente el área se emplearán especies autóctonas. Debería estudiarse la vegetación del entorno, tanto como indicadora de las condiciones de supervivencia, como para facilitar la recuperación cromática de la superficie.

\section{Otros elementos}

Las soluciones que incluyen estructuras como aparcamientos, vías de comunicación, o la construcción de naves industriales u otro tipo de edificación, deben plantearse teniendo en cuenta la capacidad portante del relleno y previendo un asentamiento mayor, debido a las sobrecargas. Para asegurar las condiciones de cimentación, cuando no es suficiente con una capa de cobertura, se puede sanear la zona de apoyo sustituyendo el residuo por materiales de mejor calidad, mejorar los propios materiales mediante compactación, consolidación dinámica o precarga, o recurrir a la cimentación en profundidad, con el uso de pilotes.

En cualquier caso no deben instalarse edificaciones residenciales sobre residuos, por el riesgo de migración del gas de vertedero entre las mismas. Como norma general deberían evitarse construcciones cerradas a nivel del suelo sobre el vertedero o en las cercanías, así como cualquier instalación subterránea cercana al perímetro del vertedero a menos de $50 \mathrm{~m}$ del mismo (DEP Florida 2001). En todo caso, cualquier estructura que se instale debe prevenir la explosión por combustión de gases, con una buena ventilación y utilizando conducciones eléctricas con protección antiexplosiva. Por otro lado, si no se ha impermeabilizado la superficie, deben evitarse los 
elementos de drenaje, para limitar el riesgo de filtración del agua hacia el residuo antiguo.

\section{Vigilancia postclausura}

Tras el cierre da comienzo el período postclausura. Se trata de un período de largo plazo en el que el relleno sigue activo, pero todos los procesos se ven ralentizados, por efecto de la cobertura y la desaparición progresiva de la materia degradable. La actividad de vigilancia o seguimiento postclausura se encarga de asegurar que los riesgos ambientales se mantienen bajo control, que era el objetivo del cierre y clausura. Se trata por tanto de controlar los elementos principales de riesgo: lixiviados, gases y estabilidad geotécnica.

Una herramienta fundamental para ello es la inspección visual periódica de las instalaciones, en la que se puede detectar agrietamiento de las capas de cobertura, deterioro en conducciones y chimeneas, estados erosivos excesivos e incluso emanaciones inesperadas de gas o líquido.

El efecto de los lixiviados puede controlarse a través de la composición de las aguas superficiales y subterráneas aguas arriba y aguas abajo del relleno. Para ello, según la topografía, hidrografía y configuración del vertedero, se deben definir puntos de control que permitan evaluar cambios relevantes de composición en todos los cursos de agua que se puedan ver afectados.

En cuanto al biogás, debería controlarse la cantidad y composición emitida a través de las chimeneas o líneas diferenciadas, de manera que se pueda seguir la evolución de las distintas zonas del vertedero.

Para asegurar la estabilidad, se realizarán controles de asientos en distintas zonas de la superficie, complementados con seguimiento de movimientos horizontales en los taludes de cierre y zonas más conflictivas.

Todos estos aspectos formarán parte del programa de monitoreo del sitio siempre que los riesgos asociados sean significativos. Esta información debe permitir detectar situaciones excepcionales e introducir medidas correctoras con suficiente antelación. La frecuencia de medidas recomendable, por tanto, depende de la velocidad de los procesos del vertedero y por eso sería conveniente redefinirla según los datos que se vayan registrando. Debería ser más frecuente el seguimiento cuando el vertedero registre cambios más rápidos, normalmente cuanto más joven. Como norma de mínimos, podría plantearse una frecuencia de seguimiento de aguas, gases y asentamientos semestral, tal y como se propone, por ejemplo, en MAM (2006).
En cualquier caso el Plan de Seguimiento debe marcar claramente los criterios de actuación es decir, los valores de las variables observadas a partir de los cuales se debe actuar, así como planes de emergencia ante detecciones extraordinarias.

\section{Mantenimiento}

A pesar del cierre, en el vertedero seguirá operando el sistema de regulación, tratamiento y/o transporte de los lixiviados y gases, mientras estos se sigan produciendo. Además, el nuevo uso del relleno y su control como pasivo ambiental requiere un mantenimiento continuo de los elementos de cierre y reinserción: capa de sellado, incluidos taludes, bermas, caminos de servicio, elementos de cerramiento y señalización, los sistemas de evacuación de pluviales, lixiviados y de gases, los elementos de vigilancia y control y las plantaciones y/o estructuras.

Es habitual la rotura o agrietamiento de cunetas, conducciones y chimeneas por efecto del asentamiento diferencial del residuo, la oxidación de elementos metálicos o la obturación de tubos. El plan de mantenimiento debe ser capaz de detectar estas dificultades e irlas solucionando para que no constituyan un problema.

\section{EJEMPLOS EN IBEROAMÉRICA}

A pesar del gran número de sitios pendientes de ser saneados y cerrados, en Iberoamérica también existen muchos casos de vertederos que han sido reinsertados exitosamente para nuevos usos. En lugar de una recopilación extensa, en este apartado hemos preferido recoger, con el detalle que permite la extensión de un artículo de este tipo, algunos casos que los autores conocen de cerca y que pueden servir de referencia para los que quedan pendientes. Se incluyen cinco ejemplos diferentes, comenzando por dos casos de vertederos grandes en Chile, cuya reinserción, ambos como espacio de uso público, se ha planteado clausurando los residuos con actuaciones simples, tratando de minimizar el costo. En el tercer caso, en España, es similar el uso final del lugar, como parque público, pero la solución técnica, en la que se hace hincapié, fue muy distinta, con mayor tecnificación y por tanto coste, y el entorno también, pues no existía asentamiento residencial alrededor del vaso de vertido. A continuación se ha elegido un caso en Brasil, destacado por las implicaciones sociales del cierre del lugar $\mathrm{y}$, finalmente, se presenta un ejemplo de solución con levantamiento del residuo y posterior confinamiento in situ, en un pequeño vertedero de Argentina. 


\section{La Feria (Chile)}

Los trabajos de reinserción del relleno sanitario de La Feria, en Santiago de Chile, son uno de los ejemplos de referencia en el ámbito iberoamericano.

Se trata de un antiguo vertedero situado en un área inicialmente reservada para uso urbano, que luego se convirtió en una cantera a cielo abierto hasta alcanzar una superficie aproximada de $800 \times 400 \mathrm{~m}^{2}$, con $20 \mathrm{~m}$ de profundidad media. Desmantelada la explotación, el lugar recibió los residuos sólidos de la ciudad (aproximadamente $2300 \mathrm{t} / \mathrm{d}$ ) durante 7 años, entre 1977 y 1984. En 1982 comenzó el aprovechamiento del gas vertedero, con instalación de más de 100 pozos para recuperación de hasta $86000 \mathrm{~m}^{3} / \mathrm{d}$ (GRS-PUCV 2008).

Tras su abandono en los últimos años ochenta, al quedar rodeado de zonas pobladas, se convirtió en un área con grandes problemas de acumulación de residuos, delitos e insalubridad. Enfrentando estos problemas, el Servicio de Vivienda y Urbanismo contrató, dentro del programa de Forestación Urbana, el proyecto de sellado y reinserción del área en 1993.

Este relleno es ejemplo de los antiguos vertederos, de los que se dispone de información muy escasa que ayude a afrontar el proyecto de reinserción y en los que, por supuesto, no se han ido abordando acciones de sellado al desarrollarse la operación. Sin embargo, por su seguimiento posterior, sirve también de referencia al plantear proyectos de reinserción en sitios similares.

El cierre se realizó con una capa de tierra en espesores entre 30 y $50 \mathrm{~cm}$, aumentada en superficie con suelo orgánico para desarrollo de la vegetación. Hoy en día, el proyecto de reinserción en su primera etapa ha finalizado, dando paso a un gran parque de 11,7 ha gestionado por la Unidad de Parques Urbanos del Parque Metropolitano, denominado Parque André Jarlan, que se disfruta desde hace más de 15 años. Las fases 2 y 3 , con una superficie parecida, serán acometidas en los próximos años.

Como parte de las acciones de reinserción se plantaron diversas especies vegetales arbóreas y arbustivas, muchas de las cuales fueron objeto de investigación previa en el vertedero experimental La Gloria (Limache, Chile) (GRS-PUCV 2003), y se instalaron infraestructuras recreacionales para el público en general (pistas de juego).

Entre los problemas detectados durante los primeros años de reinserción, que se atenuaron con medidas correctoras, destaca el inadecuado drenaje de aguas superficiales en algunas zonas, al alterarse las pendientes iniciales al cabo de un tiempo por los asentamientos sufridos en el relleno. Por otro lado, daños a la vegetación plantada por la migración de gases en superficie, pusieron de manifiesto que la red de chimeneas instaladas no era capaz de evacuar todo el gas generado en el interior, pues en algunas zonas el residuo no permitía su movimiento hacia los conductos, y favorecía el escape por el contorno. La migración del gas en superficie y algún afloramiento de lixiviado generó anoxia vegetal por saturación en las zonas radiculares. Con diferencias entre distintas especies, se presentaron pérdidas entre el 10 y el 80 por ciento de la biomasa (GRS-PUCV 2004).

A pesar de estas dificultades, el impacto sobre la población circundante es positivo: algunas viviendas que por años tapiaron sus ventanas para evitar molestias por olores y vectores, en la actualidad han recuperado sus ventanales y accesos para disfrutar del paisaje que les ofrece el parque.

\section{Lo Errázuriz (Chile)}

El vertedero Lo Errázuriz dio servicio a 15 municipios del área metropolitana de Santiago de Chile, que depositaron los RM durante 10 años (entre 1985 y 1995). El sitio corresponde a un antiguo pozo de extracción de áridos con $35 \mathrm{~m}$ de profundidad media. Ocupa 40 ha, de las cuales 27 ha son de propiedad de EMERES (Empresa Municipal de Residuos), en una zona urbana con viviendas en su entorno.

Desde el principio se concibió como relleno sanitario en área, con cobertura intermedia y recuperación de biogás a través de chimeneas interconectadas. Por otro lado, dada su proximidad a la población, estuvo sometido a estricta vigilancia sanitaria, incluyendo el control de plagas (perros, ratas y moscas). La gestión de lixiviado se realizaba aprovechando la capacidad de almacenamiento en el seno del residuo, monitoreando las condiciones de humedad para no comprometer la estabilidad.

Tras su puesta en marcha, ante la fuga de biogás que afectó a viviendas del entorno, se mejoró la impermeabilización lateral, incluyendo tres capas: lámina de polietileno de alta densidad, gaviones de ventilación para canalización lateral del gas y hormigón proyectado.

Durante los años de explotación, se vertieron un total de 8828000 t de RM, de los que se se recuperaron $400000000 \mathrm{~m}^{3}$ de biogás. En 1995 se había sobrepasado la capacidad del lugar, y aumentado las cotas de vertido previstas, lo que había generado problemas de olores y emisiones. Durante ese año se realizaron los primeros estudios para el cierre y reinserción, que incluyeron levantamientos topográficos, ensayos de residuos, pruebas de infiltración, evaluación de lixiviados y emisiones gaseosas y pruebas de bombeo y extracción forzada (GRS-PUCV 2004). 
El proyecto inicial de reinserción contemplaba la recuperación del área como zona recreativa para la población circundante, tratando de resarcirla de las molestias sufridas durante la explotación. Las obras de clausura incluyeron una capa de cobertura y regularización final de 20 a $30 \mathrm{~cm}$ de tierra, instalada progresivamente en distintas zonas. Aunque no estaba previsto en proyecto, sobre esta primera capa hubo zonas donde se vertieron escombros a posteriori. Conseguidas las pendientes adecuadas para evacuación de la escorrentía, se añadieron $10 \mathrm{~cm}$ de cobertura adicional, y sobre ésta, según las zonas de uso final, la capa de suelo substrato para la vegetación.

Hoy en día se cuenta con el proyecto de cierre, sellado y reinserción definitivo, que contempla su recuperación como espacio público (GRS-PUCV 2014). La primera fase del proyecto cuenta con 1260000 USD de presupuesto, financiados mediante convenio entre el Gobierno Regional, el Ministerio de Medio Ambiente y el PNUD (Programa de las Naciones Unidas para el Desarrollo). Actualmente más de 30 vertederos han sido cerrados sellados y reinsertados en Chile con este modelo de financiación, basado en recursos del BID (Banco Interamericano de Desarrollo).

\section{Valdemingómez (España) \\ Clausura}

Este caso es un ejemplo de instalación que recibió los residuos de una gran ciudad durante largo tiempo. El antiguo vertedero de Valdemingómez estuvo en servicio durante 22 años, desde 1978 hasta 2000, recibiendo hasta un total de 21 millones de toneladas de RM generados en Madrid (España), ocupando una superficie de más de 100 ha.

Las primeras investigaciones previas a su sellado, encaminadas a cuantificar las opciones de aprovechamiento del gas de vertedero, se plantearon varios años antes de su cierre, en 1995. Pero el proyecto de sellado y restauración se desarrolló tras la clausura de las instalaciones. Las obras se iniciaron un año más tarde, prologándose durante 22 meses.

El vertedero contaba con retención y gestión de los lixiviados recogidos mediante recirculación en superficie, y la operación a lo largo de los años había sido controlada técnicamente. Por ello en este caso no fue necesario un saneamiento previo y, a pesar de que el proyecto de cierre se abordó tardíamente, tampoco se requirió gran movimiento de tierras para modificar las pendientes de los taludes. Los trabajos de reperfilado se limitaron a la construcción de bermas intermedias para estabilizar la pendiente en los taludes más altos.
Para las capas de sellado se diferenciaron dos zonas: la plataforma de coronación, con pendientes muy ligeras (por debajo del $5 \%$ ) y los taludes laterales (TMA 2003). Mientras que en las zonas más planas se utilizó una cobertura mixta, que combinaba materiales naturales y sintéticos, en los taludes se optó por una solución totalmente sintética. El cuadro III reúne las distintas capas consideradas en cada zona de este vertedero. Al quedar la zona a sellar muy próxima al perímetro de la finca del vertedero, fue necesario diseñar una solución especial para anclar las capas sintéticas, mediante anclaje "artificial" con gaviones de $1 \mathrm{x} 1 \mathrm{~m}$.

Para interceptar y evacuar la escorrentía superficial evitando problemas de erosión se construyeron una cuneta de cabecera, en el perímetro de la coronación, y cunetas de evacuación al pie del talud, junto con las correspondientes bajantes.

La balsa utilizada durante la explotación para regulación de los lixiviados se aprovechó como depósito previo al transporte de los lixiviados a una planta de tratamiento avanzado.

El proyecto de desgasificación incluyó 280 pozos de captación, con 10 estaciones de regulación y una central de extracción principal con cuatro soplantes y dos centrales secundarias. 8 motogeneradores de $2124 \mathrm{kWe}$ y una caldera de vapor-turbina-alternador $1960 \mathrm{kWe}$ más una estación transformadora (de $6300 \mathrm{~V}$ a 45000 $\mathrm{V})$ de $23000 \mathrm{kVA}$. Las instalaciones, diseñadas para $10000 \mathrm{Nm}^{3} / \mathrm{h}$, se complementan con 2 antorchas para tratamiento del gas sobrante (Erice 2003).

Estas soluciones de clausura se complementan con un plan de seguimiento ambiental y mantenimiento previstos para 30 años.

\section{Reinserción}

Una ventaja de este vertedero frente a otros vertederos "municipales", es que en este caso el crecimiento demográfico a lo largo de los años no ha llegado a absorber el espacio disponible entre el área de vertido y el núcleo poblacional principal. Por ello para la reinserción se planteó integrarlo en un gran Parque Forestal (de 100 ha). Aprovechando edificaciones de explotación, como la antigua nave de descarga, se creó un centro de educación ambiental que incluye un recorrido por los centros de tratamiento de residuos que se han instalado en el entorno.

El proyecto de reinserción tuvo en cuenta la localización del vertedero, adyacente a una Zona de Especial Protección de las Aves, asociada a dos ríos cercanos. La revegetación se diseñó a partir de estudios previos que, basados en los mapas de series de vegetación en el área, tienen en cuenta el efecto 
CUADRO III. CAPAS DE SELLADO EMPLEADAS EN VALDEMINGÓMEZ (ALTA TECNIFICACIÓN)

\begin{tabular}{|c|c|c|}
\hline & $\begin{array}{l}\text { Solución sintética } \\
\text { (en taludes) }\end{array}$ & $\begin{array}{l}\text { Solución mixta } \\
\text { (en coronación) }\end{array}$ \\
\hline Soporte para vegetación & $\begin{array}{l}20 \mathrm{~cm} \text { de tierra vegetal }+ \text { compost }+ \\
\text { manta orgánica (yute) }\end{array}$ & $20 \mathrm{~cm}$ de tierra vegetal + compost \\
\hline Cobertura de tierra & 80 a $130 \mathrm{~cm}$ de tierra seleccionada & 80 a $130 \mathrm{~cm}$ de tierra seleccionada \\
\hline Drenaje de pluviales & Geodrén + Geotextil de poliéster & $\begin{array}{l}30 \mathrm{~cm} \text { grava con tubo dren entre } 2 \\
\text { geotextiles de poliester }\end{array}$ \\
\hline Impermeabilización & Doble Lámina de PEAD de $1 \mathrm{~mm}$ & Doble Lámina de PEAD de $1 \mathrm{~mm}$ \\
\hline Drenaje de gases & Geodrén entre 2 geotextiles de PP & Geodrén entre 2 geotextiles de PP \\
\hline Regularización & Tierra & Tierra \\
\hline
\end{tabular}

antrópico sobre el paisaje, que conduce a etapas más degradadas en cada serie. Establecida la vegetación a plantar, se definieron las capas soporte sobre la cobertura del vertedero, como una combinación de tierra vegetal de la zona y compost obtenido del tratamiento de los lodos de depuración de agua residual de la ciudad (Cuadro III).

Como primera medida para atenuación del impacto visual y defensa frente a la erosión, se realizó una hidrosiembra de gramíneas, sobre la manta orgánica de yute. Posteriormente se plantaron hasta 300000 arbustos de 35 especies y 50000 árboles de 16 especies. Para evitar problemas de adaptación, la plantación se realizó con ejemplares jóvenes de plantas autóctonas. Con el objetivo de agrupar una representación completa de los ecosistemas naturales en la zona, se definieron siete áreas en todo el Parque Forestal: encinar, quejigar, melojar, vegetación riparia, pinares, vegetación yesífera y cultivos leñosos. En cada una, las especies básicas (la encina en el primer caso), aparecen acompañadas por otras (olivo, cornicabra, quejigo, jara, retama en el encinar), que aseguran la protección del suelo y enriquecen la biodiversidad. Para distribuir las especies sobre el antiguo vertedero se diferenciaron las zonas de meseta frente a los taludes, con mayor impacto visual y mayor riesgo de erosión. En estos últimos, las zonas de umbría se plantaron especies con mayor necesidad de humedad (quejigos y arces), mientras que en las de solana se establecieron especies más xerófilas.

Además se instaló la infraestructura de riego, por aspersión en algunas zonas y goteo en otras, con depósito regulador y bombeo. Hoy en día se está empleando para el riego agua regenerada en una estación depuradora de aguas residuales urbanas cercana (EDAR Sur). La balsa de regulación, para almacenamiento del agua, se ha diseñado como lago ornamental del complejo.

\section{Presupuesto}

Las obras de cierre, sellado y reinserción implicaron en su día un coste total de $73500000 €$ : $25800000 €$ el sellado, $6400000 €$ la desgasificación, $17400000 €$ las instalaciones para valorización energética del gas y $9800000 €$ de reinserción (Erice 2003). El resto correspondió a gastos de asistencia técnica y otros gastos menores, como publicidad, seguros y licencias.

\section{Canabrava (Brasil)}

El botadero de Canabrava recibió los RM de Salvador de Bahía durante más de 20 años, desde 1973. Los residuos eran extendidos sin control en una zona de 69 ha situada entre dos ríos, en la Bahía de Juguaribe. Esta gran masa de basura incontrolada (más de 7000000 t), generó problemas ambientales de contaminación por infiltración de aguas y migración de gases. Cuando se acometió el proyecto de cierre, en 1997, más de mil badameiros (recogedores de basura o recicladores informales) vivían en el lugar, atestado de insectos y otros animales. Por eso al acometer el proyecto de cierre las prioridades comprendían, junto con la recuperación del área degradada, acabar con el trabajo infantil, insertar en el mercado laboral a los exbadameiros y diseñar una estrategia de desarrollo e inclusión social.

El proyecto, acometido en cooperación entre el municipio y la Agencia Canadiense de Desarrollo Internacional, a través de la Iniciativa Ciudades Sostenibles, se abordó con una estrategia global de actuación sobre la gestión de los residuos en la ciudad. El primer paso fue la apertura de un nuevo relleno sanitario (HABITAT 2004). El cierre de Canabrava se ejecutó con espesores mínimos de tierra sobre los residuos reperfilados en las zonas con problemas de estabilidad, e incluyó la recolección de gases mediante chimeneas verticales conectadas (extracción 
activa) para su quemado controlado, y la intercepción de lixiviados que escapaban libremente en el contorno. Ante la escasez de recursos económicos, se aprovecharon materiales de desecho en las obras: neumáticos para los sistemas de desgasificación, chatarra para las conducciones de drenaje, etc. En la revegetación se emplearon plantas autóctonas. Por otro lado, y en paralelo, se desarrollaron campañas educativas hacia la separación de residuos así como un plan de recogida selectiva de reciclables.

El resultado de la reinserción es el parque socioambiental de Canabrava, abierto en 2003, tras 7 años de trabajos. Además de zonas de ocio y esparcimiento, el parque incluye un centro de separación de materiales manejado por una cooperativa de antiguos recicladores informales, una planta de compostaje, varias unidades de recuperación de residuos industriales, y una pequeña planta de generación de energía a partir del gas recolectado.

Como complemento, se pusieron en macha planes de reinserción laboral de los adultos y de integración de los menores, así como de seguimiento ambiental y de la población en el área, y mantenimiento del lugar y las nuevas instalaciones. El proyecto fue reconocido por el programa Buenas Prácticas Latinoamericanas y del Caribe de Naciones Unidas (HABITAT 2004).

\section{Gualtallary (Argentina)}

El vertedero de Gualtallary, situado al pie de la Cordillera de Los Andes, en la región central de la Provincia de Mendoza recibió una cantidad total aproximada de 14000 toneladas de RM generados por la población de la ciudad de Tupungato entre los años 1985 (16 700 hab.) y 1992 (22 370 hab.) (DEIE 2004). En ese periodo la cobertura del servicio era del 70 \% (DEIE 2009). La eliminación de los RM se realizó sobre suelo superficial sin preparación previa, con cobertura semanal, compactación de $0.5 \mathrm{t} / \mathrm{m}^{3}$ y en una extensión superficial de 2 ha. Este vertedero estaba situado en el interior de una propiedad privada, contratada por la administración municipal para la disposición final de los RM. Al cesar el ingreso de residuos no se implementaron medidas para el control de lixiviados ni para la emisión de gases, por lo que se desconocían las consecuencias relacionadas con su existencia.

A lo largo de los años, las condiciones edáficas y el desarrollo de nuevas técnicas de riego produjeron una importante demanda de tierras para el cultivo de la vid en la región (Cortés et al. 2006, DGI 2007), por lo que el Municipio de Tupungato resolvió llevar adelante un plan para la clausura y posterior reinser- ción de este vertedero para uso agrícola. Este plan se inició en el año 2009 cuando se realizaron estudios de la masa de RM, del suelo natural y de la presencia de contaminantes en el entorno del lugar para identificar las rutas de migración, las vías de transporte y los potenciales receptores (Llamas y Mercante 2011). Las determinaciones realizadas sobre las muestras obtenidas, confirmaron la necesidad de eliminar el riesgo en el origen (Llamas et al. 2011).

Para lograr ese objetivo se propusieron dos alternativas: 1) Trasladar la totalidad de los RM a una instalación provista de los elementos de control necesarios; 2) Implementar una celda para la contención segura de los RM en el lugar. La valoración económica de ambas alternativas favoreció la adopción de la segunda alternativa, lo que permitió al Municipio de Tupungato iniciar el procedimiento licitatorio para adjudicar la ejecución de las obras necesarias para implementar la acción correctiva seleccionada en el año 2010.

Se retiró la capa de suelo que cubría los RM, conformando montículos con diferentes granulometrías para su empleo posterior como material de cubierta. Para la extracción de la masa de RM fue necesario realizar un acopio especial para aquellos que, por sus características peligrosas, debían ser gestionados por separado (pilas, baterías y jeringas).

Las dimensiones de la celda fueron las siguientes: $110 \mathrm{~m}$ de largo, $30 \mathrm{~m}$ de ancho y $4 \mathrm{~m}$ de profundidad, con taludes de $45^{\circ}$. Se excavó la celda de confinamiento, se extendió una capa de arcilla como material de base que fue compactada con rodillo hasta lograr un valor de permeabilidad de $1.05610 \times 10^{-7} \mathrm{~cm} / \mathrm{s}$. Los RM se reubicaron en la celda en capas sucesivas que fueron compactadas hasta lograr una densidad de $1.72 \mathrm{~g} / \mathrm{cm}^{3}$. La conformación de la barrera superior se realizó con la aplicación de $0.50 \mathrm{~m}$ de suelo granular, seguido de $0.50 \mathrm{~m}$ de suelo fino, sobre el cual se implementó una capa de $0.20 \mathrm{~m}$ de arcilla debidamente compactada, hasta alcanzar la profundidad total de $1.20 \mathrm{~m}$ de material de cobertura (Llamas et al. 2013). Esta profundidad permite la implantación de viñedos sin que se vea afectada la integridad de la barrera superior.

\section{CONSIDERACIONES FINALES}

Los vertederos controlados o rellenos sanitarios se presentaron a partir de los años sesenta como una solución sanitaria para el manejo de los residuos sólidos urbanos. Sin embargo hoy en día se consideran 
"pasivos ambientales". La presencia de contaminantes que pueden liberarse al suelo, las aguas o la atmósfera, degradando los recursos naturales, constituyen un riesgo significativo que se prolonga durante décadas tras el cese de los vertidos. Los proyectos de cierre y sellado deben mitigar estos impactos, e ir acompañados de una reinserción que atenúe el impacto paisajístico del vertedero. Esta última fase tiene especial importancia en rellenos explotados en las cercanías de poblaciones. Debe diseñarse de manera que devuelva el lugar a la sociedad, y en particular a la población que se ha visto afectada durante años por molestias ambientales y socioeconómicas, otorgándole una mejor calidad de vida.

Las soluciones de cierre, sellado y reinserción suponen un esfuerzo técnico y económico importante. Existen hoy en día, como se ha descrito, soluciones muy avanzadas técnicamente que consiguen anular el pasivo ambiental en corto plazo. Pero también son válidas alternativas más sencillas, que hacen compatible un nuevo uso del terreno con los procesos de degradación que continúan en el residuo, a un coste menor.

Al tratarse de problemas globales y comunes a todas las poblaciones, en la actualidad distintos organismos internacionales ofrecen programas de ayuda para financiar este tipo de proyectos. Por otro lado, en los casos en que es posible aprovechar el biogás remanente, el proyecto de captación y aprovechamiento puede incorporar las obras de saneamiento. Se trata en definitiva de explotar al máximo las potencialidades del lugar (uso público, generación de energía, etc.), reduciendo al mínimo los riesgos aparejados.

\section{REFERENCIAS}

ACLIMA. Asociación Cluster de Industrias de Medio Ambiente de Euskadi (2014) ITZULBIDE Proyecto Integración de instalaciones solares fotovoltaicas sobre vertederos clausurados y sobre cubiertas industriales en plantas de tratamiento de residuos. Memoria final [en línea]. HYPERLINK “http://empleaverde.es/sites/ default/files/memorias-proyectos/aclima.pdf $\% 20 \% 20$ 27/12/2016" http://empleaverde.es/sites/default/files/ memorias-proyectos/aclima.pdf 16/07/2014

Acurio G., Rossin A., Teixeira P.F. y Zepeda F. (1997) Diagnóstico de la situación del Manejo de Residuos Sólidos Municipales en América Latina y El Caribe. No. ENV.97-107. Banco Interamericano de Desarrollo (BID) - Organización Panamericana. Washington D.C., Estados Unidos, 130 pp.
Bolton N. (2012) Landfill Odors: I see, therefore I smell. MSW Management. Septiembre - Octubre 2012. http:// foresternetwork.com/daily/waste/landfill-gas/landfillodors-i-see-therefore-i-smell/ 10/07/2014.

Calvo F. Moreno B. Zamorano M. y Szantó M. (2005) Environmental diagnosis methodology for municipal waste landfills. Waste Manage. 25(8), 768-779. http:// dx.doi.org/10.1016/j.wasman.2005.02.019

Canaleta A. y Ripoll G. (2012) Experience of landfill mining in Mallorca (Balearic islands, Spain). The philosophy of the perpetual landfill. SUM 2012 Symposium on Urban Mining. Bérgamo, Italia. $21-23$ mayo, 2012. CD-ROM.

Carreras N. (1998) Guía para la extracción y utilización del gas de vertedero. CIEMAT, Madrid, España, 112 pp.

Colomer F. y Gallardo A. (2007). Identificación de peligros asociados a un vertedero controlado. Residuos: Revista Técnica. 97, 86-95.

CONAM/CEPIS/ OPS (2004). Guía técnica para la clausura y conversión de botaderos de residuos sólidos. Consejo Nacional del Ambiente. Centro Panamericano de Ingeniería Sanitaria y Ciencias del Ambiente. Lima. Perú. 98 pp.

Cortés J., Casa A., Pasino M., Yamin M. y Terrizazano C. (2006). Fajas oblicuas de deformación neotectónica en precordillera y cordillera frontal $\left(31^{\circ} 30^{\prime}-33^{\circ}\right.$ 20' LS): Controles Paleotectónicos. Rev. Asoc. Geol. Argent. 61, 639-646.

Craig L. (2011). New York Landfill Goes Green Undercover. Earth Techling. [en linea]. http://earthtechling. com/2011/09/new-york-landfill-goes-green-undercover/ 01/07/2014.

DEIE (2004). Encuesta de Condiciones de Vida de los Hogares Rurales. Distritos Rurales de la Provincia de Mendoza. Dirección de Estadísticas e Investigaciones Económicas. Subsecretaría de Agricultura y Programación Económica. Ministerio de Economía. Gobierno de Mendoza. $94 \mathrm{pp}$.

DEIE (2009). Sistema Estadístico Municipal. Estadísticas Socio-Económicas Mendoza, 1991-2009. Tupungato. Serie Estadísticas Municipales. Publicación No 9. Dirección de Estadísticas e Investigaciones Económicas. Ministerio de Producción, Tecnología e Innovación. Gobierno de Mendoza. 79 pp.

DEP Florida (2001) Guidance for disturbance and use of old closed landfills or waste disposal areas in Florida. Departamento de Protección Ambiental, Florida, Estados Unidos.

DGI (2007). Plan Director del Río Tunuyán. Secretaría de Agricultura, Ganadería, Pesca y Alimentación de la Nación. Gobierno de Mendoza. Departamento General de Irrigación. Mendoza, 95 pp. 
Duffy, D.P. (2005) Landfill Economics Part III: Closing Up Shop. Municipal Solid Waste Management. Septiembre - Octubre 2005. [en linea]. http://www.mswmanagement.com/MSW/Articles/1504.aspx? format $=2$ $10 / 04 / 2015$

EA (2004) Guidance on the management of landfill gas. Landfilll Directive. Landfill Task Group N3. Environmental Agency, Gran Bretaña.

Edil T. B., Ranguette V. J. y Wuellner W. W. (1990) Settlement of municipal refuse. En: Geotechnics of waste fills: Theory and practice (A. Landva y G. D. Knowles) ASTM, West Conshohocken, Estados Unidos, pp. 225-239.

Erice I. (2003) La energía de la basura. Ambienta (JulioAgosto), pp. 57-62.

Esteban-García A., Muñoz J.M., Szantó M., Tejero I. (2001) The other dimension in waste management: The informal sector and socio-labour insertion. Proceedings, Sardinia 2001. Eighth International Waste Management and Landfill Symposium. S. Margherita di Paula, Cagliari, Italia, 1 al 5 de octubre de 2001.

Eurostat (2013) Sustainable development in the European Union. 2013 monitoring report of the EU sustainable development strategy. Oficina de Publicaciones de la Unión Europea, Luxemburgo, pp. 284.

FEMP (2011) Estudio del potencial de reducción de emisiones en los vertederos municipales. Federación Española de Municipios y Provincias. [en linea]. http://www.redciudadesclima.es/files/documentacion/ b168f33ddf6a49c7d32b5b6dd0d6662b.pdf 1/07/2014.

GRS-PUCV (Grupo de Residuos Sólidos, Pontificia Universidad Católica de Valparaíso) (2003) Propuesta metodológica para evaluar el efecto del biogás sobre el desarrollo de especies vegetales en rellenos sanitario: caso Prosopis chilensis. Proyecto DI 202.792/2002, FONDEF - CONICYT Chile.

GRS-PUCV (Grupo de Residuos Sólidos, Pontificia Universidad Católica de Valparaíso) (2004) Metodología integrada para rehabilitar rellenos sanitarios y tanques de relave. Proyecto D00I1101, FONDEF-CONICYT Chile.

GRS-PUCV (Grupo de Residuos Sólidos, Pontificia Universidad Católica de Valparaíso) (2008) Estudio explorativo de las emisiones de biogás del Parque André Jarlan ex vertedero La Feria. SERVIU, Servicio Metropolitano de Vivienda y Urbanismo Chile.

GRS-PUCV (Grupo de Residuos Sólidos, Pontificia Universidad Católica de Valparaíso) (2014) Proyecto Definitivo de Cierre, Sellado y Reinserción del ExVertedero de RSD de Lo Errázuriz.

GTZ. Subsecretaria de Ecología del Gobierno del Estado de México. (2002). Manual para la rehabilitación, clausura y saneamiento de vertederos o tiraderos a cielo abierto en el estado de México. 72 pp.
HABITAT (2004) Conversión de un vertedero en parque socio-ambiental (Salvador de Bahia, Brasil). Ciudades para un futuro más sostenible. [en linea]. http://habitat. aq.upm.es/bpal/onu04/bp2588.html 02/07/2014

Hogland W., Marques M. y Nimmermark S. (2004) Landfill mining and waste characterization: a strategy for remediation of contaminated areas. Journal of Material Cycles and Waste Management 6, 119 a 124.

ISWA (2010). Guía de operaciones. Grupo de trabajo sobre rellenos sanitarios. $104 \mathrm{pp}$.

ITRC 2006. Evaluating, Optimizing, or Ending Post-Closure Care at MSW Landfills Based on Site-Specific Data Evaluations. ALT-4. Washington, EE.UU.: Interstate Technology \& Regulatory Council, Alternative Landfill Technologies Team., Washington, Estados Unidos.

Krook J., Svensson N. y Eklund M. (2012) Landfill mining: A critical review of two decades of research. Waste Manage. 32, 513-520. http://dx.doi.org/10.1016/j. wasman.2011.10.015

Laner D., Crest M., Scharff, H., Morris J.W.F. y Barlaz M.A. (2012) A review of approaches for the long-term management of municipal solid waste landfills. Waste Manage. 32, 498 - 512. http://dx.doi.org/10.1016/j. wasman.2011.11.010

Llamas S. y Mercante I. (2011). Restauración de sitios contaminados con residuos: En: Residuos sólidos un enfoque multidisciplinario. (L. Márquez, Ed). Libros en red, Vol. I, pp 443-487.

Llamas S., Mercante I. y Martinengo P. (2011). Metodología de caracterización de pasivos ambientales generados por la eliminación de residuos sólidos urbanos. Memorias. VI Encuentro de Investigadores y Docentes en Ingeniería. San Rafael, Mendoza. 11 al 13 de Mayo, 2011. CD-ROM.

Llamas S., Mercante I, Martinengo P. (2013). Reinserción de un antiguo basural para uso agrícola en Argentina. Rev. Int. Contam. Ambie. 29 (Sup. 3) 99-105.

MAM (2001) Real Decreto 1481/2001, de 27 de diciembre, por el que se regula la eliminación de residuos mediante depósito en vertedero. Ministerio de Medio Ambiente. Gobierno de España. Boletín Oficial del Estado. 29 de enero de 2002.

MAM (2006) Borrador de orden MAM/.../2006, por la que se desarrollan los Anexos I y III del Real Decreto 1481/2001 por el que se regula la eliminación de residuos mediante depósito en vertedero. Ministerio de Medio Ambiente. Gobierno de España.

MDE (2010) Estimated Costs of Landfill Closure. Fact Sheet. Maryland Department of the Environment. EE.UU. pp. 2.

ME (2001) A Guide for the Management of Closing and Closed Landfills in New Zealand. Ministerio de Medio Ambiente de Nueva Zelanda. 
MINSAL (2007) Decreto Supremo 189. Reglamento sobre condiciones sanitarias y de seguridad básicas en los rellenos sanitarios. Ministerio de Salud. Gobierno de Chile. Diario Oficial. 5 de Enero de 2008.

Olaeta J., Espinace R., Szantó M. y Palma J. (1997) Experiencias de reinserción de vertederos mediante la implantación de una cubierta vegetal en Actas del XII Congreso Chileno de Ingeniería Sanitaria y Ambiental. Copiapó, Chile, Octubre de 1997.

Reinhart D.R. y Townsend T.G. (1998) Landfill Bioreactor Design and Operation. Lewis Publishers. Estados Unidos.

Rondón E. y Szantó M. (2012) Ecoeficiencia y desarrollo de infraestructura urbana sostenible en Asia y América Latina: Residuos y reducción de gases de efecto invernadero: el caso de Chile. Cepal Naciones Unidas, Santiago de Chile. pp.57.

Szantó M., Muñoz J., Calvo, F., Zepeda F., Cantanhede, A., Acurio G. y Civallero T. (1996) Manejo y operación de un vertedero. Red Latinoamericana y del Caribe para la Capacitación y la Cooperación Técnica Mediante la Educación a Distancia. Córdoba, Argentina.

Scharff, H. (2007) The Role of Sustainable Landfill In Future Waste Management Systems. Informe de la ISWA International Solid Waste Association [en linea]. http://www.iswa.org/uploads/tx_iswaknowledgebase/618166_Paper.pdf 01/02/2014.

Tansel B., Londono V., Kumar P. y Sizirici, B. (2010). Closed Landfills as Power Parks: Technical and Eco- nomic Feasibility of Solar Energy Harvesting at Florida's Closed Landfills. Hinkley Center for Solid and Hazardous Waste Management. Gainesville, Florida, Estados Unidos, 209 pp.

Tchobanoglous G., Theisen H. y Vigil, S.(1994) Gestión Integral de Residuos Sólidos. McGraw Hill D.L. Madrid, España, 1107 pp.

Tello P., Martinez E., Daza D., Soulier M. y Terraza, H. (2010) Informe de la Evaluación Regional del Manejo de Residuos Sólidos Urbanos en América Latina y el Caribe 2010. Organización Panamericana de la Salud (OPS), Asociación Interamericana de Ingeniería Sanitaria y Ambiental (AIDIS) y Banco Interamericano de Desarrollo (BID). IDB-MG-115. AIDIS -001/2011. $164 \mathrm{pp}$.

TMA (2003) Sellado del antiguo vertedero de Valdemingómez (Madrid). Ficha Técnica. Terratest Medio Ambiente.

Toth M., Sorloaica-Hickman N. y Reinhart D.R. (2013) Converting landfill sites into sustainable energy parks. Proceedings, Sardinia 2013, 14th International Waste Management and Landfill Symposium. S. Margherita di Paula, Cagliari, Italia, 30 de septiembre al 4 de octubre de 2013. CD-ROOM.

Trotti J. (2011). Landfill as Energy Farms An Idea Whose Time has Come? MSW Management 21(2), 6.

USEPA. Agencia de Protección Ambiental de Estados Unidos (2012). Landfill Methane Outreach Program. [en linea] http://epa.gov/lmop/ 12/12/2013. 